\title{
Association of Genetic Variation in Calmodulin and Left Ventricular Mass in Full-Term Newborns
}

\author{
Iwona Gorący, ${ }^{1}$ Jarosław Gorący, ${ }^{2}$ Karolina Skonieczna-Żydecka, ${ }^{1}$ Mariusz Kaczmarczyk, \\ Grażyna Dawid, ${ }^{3}$ and Andrzej Ciechanowicz ${ }^{1}$ \\ ${ }^{1}$ Department of Clinical and Molecular Biochemistry, Pomeranian Medical University, Ulical Powstańców Wielkopolskich 72, \\ 71-111 Szczecin, Poland \\ ${ }^{2}$ Department of Cardiology, Pomeranian Medical University, Szczecin, Poland \\ ${ }^{3}$ Department of Pediatrics, Pomeranian Medical University, Szczecin, Poland
}

Correspondence should be addressed to Iwona Gorący; igor@pum.edu.pl

Received 17 July 2013; Accepted 20 September 2013

Academic Editor: Giulia Piaggio

Copyright (C) 2013 Iwona Gorący et al. This is an open access article distributed under the Creative Commons Attribution License, which permits unrestricted use, distribution, and reproduction in any medium, provided the original work is properly cited.

Calmodulin II (CALM2) gene polymorphism might be responsible for the variation in the left ventricular mass amongst healthy individuals. The aim was to evaluate the correlation between left ventricular mass (LVM) and g.474955027G>A (rs7565161) polymorphism adjacent to the CALM2 gene. Healthy Polish newborns $(n=206)$ were recruited. Two-dimensional M-mode echocardiography was used to assess LVM. Polymorphisms were determined by polymerase chain reaction-restriction fragment length polymorphism and sequencing analyses. The carriers of the $\mathrm{G}$ allele of the CALM2 polymorphism had significantly higher left ventricular mass/weight (LVM/BW) values, when compared with newborns homozygous for the A allele $\left(3.1 \mathrm{~g} / \mathrm{m}^{2}\right.$ versus $2.5 \mathrm{~g} / \mathrm{m}^{2}, P_{\text {adjusted }}=0.036$ ). The AG genotype of CALM2 was associated with the highest values of LVM/BW, exhibiting a pattern of overdominance $\left(2.9 \mathrm{~g} / \mathrm{kg}\right.$ versus $3.1 \mathrm{~g} / \mathrm{kg}$ versus $\left.2.5 \mathrm{~g} / \mathrm{kg}, P_{\text {adjusted }}=0.037\right)$. The results of this study suggest that G>A CALM2 polymorphism may account for subtle variation in LVM at birth.

\section{Introduction}

Left ventricular hypertrophy (LVH) and increased left ventricular mass (LVM) are strong risk factors for cardiovascular disease and morbidity [1]. Cardiac hypertrophy is characterized by increased cell size, cardiac remodeling of myofilaments, and increased expression of fetal genes [2]. LVM results from a complex of interaction between genetic, environmental, and lifestyle factors. Increased knowledge concerning genes involved in the modulation of LVM will lead to a better understanding of the etiopathogenesis of $\mathrm{LVH}$.

Calcium $\left(\mathrm{Ca}^{2+}\right)$ is arguably the most important messenger in cardiac muscle and plays a central role in regulating contractility, gene expression, hypertrophy, and apoptosis. It has been well described that $\mathrm{Ca}^{2+}$ transient movements regulate the transcription and gene expression that characterize the hypertrophic response of cardiomyocytes [2,3]. The levels of $\mathrm{Ca}^{2+}$ are precisely controlled.
A major sensor and mediator of intracellular $\mathrm{Ca}^{2+}$ transient movements is calmodulin $(\mathrm{CaM})$. The $\mathrm{Ca}^{2+} \mathrm{CaM}$ complex binds and activates enzymes, including protein kinases, protein phosphatases, phospholipases, nitric oxide synthases, and endonucleases. Three $\mathrm{Ca}^{2+}$ calmodulin dependent enzymes have significant roles in cardiac function: $\mathrm{Ca}^{2+}$ calmodulin-dependent protein kinase (CaMK), protein phosphatase $2 \mathrm{~B}$ (calcineurin, $\mathrm{CaN}$ ), and myosin light-chain kinase (MLCK). CaMK and CaN have been shown to play key and often synergistic roles in transcriptional regulation in cardiomyocytes [4]. It has been suggested that CaMK regulates gene expression via activation of several transcription factors $[5,6]$.

$\mathrm{Ca}^{2+}$-CaM-dependent kinase II (CaMKII), a major CaM target protein, is a uniquely regulated multifunctional regulatory enzyme. The CaMKII $\delta$ isoform is the predominant cardiac isoform $[7,8]$. There are several studies indicating the major role of CaMKII involvement in cardiac hypertrophy 
and heart failure [9]. In hypertrophic myocardium of animal models, increased activity and expression of CaMKII have been shown $[10,11]$. Experimental studies have demonstrated that transgenic mice overexpressing nuclear $\mathrm{CaMKII} \delta$ have increased incidence of cardiac hypertrophy [12]. Inhibition of nuclear CAMKII activity causes transgenic mice to have smaller hearts than their nontransgenic littermates [8]. In addition, CaMKII is involved in apoptosis signaling. It has been shown that selective inhibitors of CaMKII significantly inhibit the apoptotic response [13]. Thus, any genetic variants that directly affect CaM gene expression or function are promising as candidates involved in modulating LVM. $\mathrm{CaM}$ is encoded by a multigene family consisting of three members: CALM1, CALM2, and CALM3. There are very few studies indicating the functional role of CALM2 gene polymorphism. Mototani et al. [14] discovered that 2622A $>\mathrm{G}$ and $3001 \mathrm{G}>\mathrm{A}$ polymorphism, both located in intron 1, may be associated with osteoarthritis in the Japanese population. Liu et al. [15] indicated that CALM2 is a candidate gene for primary open-angle glaucoma. To date, only Vasan et al. [16] have demonstrated, in meta-analysis, the correlation between CALM2 polymorphism rs7565161 and echocardiographic diameter LVM in adults. The guanine to adenine transition at nucleotide position 474955027 (g.474955027 G>A, rs7565161) of human chromosome $2 \mathrm{p} 21$ is intergenic, adjacent to the CALM2 gene. However, there are no reports which have focused on the association of intergenic adjacent CALM2 polymorphisms with left ventricular mass in newborns. The factors influencing heart development during fetal life or first days of life, when external environmental factors such as diet, lifestyle, smoking or diseases have not yet had a marked impact, are still being sought. We hypothesize that adjacent intergenic CALM2 polymorphism could potentially modify LVM during fetal life and in the first period of life in newborns. In the present study, the relationships between g.474955027 G>A (rs7565161) being adjacent intergenic CALM2 gene polymorphism and LVM in a population of Polish newborns have been investigated.

\section{Materials and Methods}

2.1. Study Subjects. The study was approved by the Pomeranian Medical University ethics committee. Study subjects were informed about the project and written consents were obtained.

The population included 206 consecutive healthy Polish newborns (92 females and 114 males), born after the end of the 37 th week of gestation (from 37 to 40 weeks). Mothers in this study were healthy without any complications such as preeclampsia or eclampsia, and there was no fetal growth restriction. The scientists identifying the calmodulin genotypes were blinded to the clinical characteristics of subjects. Newborns in this study were appropriately grown for their gestational age (defined as birth mass above the 10th centile). Exclusion criteria were twins, intrauterine growth restriction, chromosomal aberrations and/or congenital malformations, or "small for gestational age," that is, below the 10th centile body length (BL), birth weight (BW), or head circumference
(HC). At birth, cord blood $(500 \mu \mathrm{L})$ of neonates was obtained for isolation of genomic DNA. The gender of the newborn, $\mathrm{BL}, \mathrm{BW}$, and $\mathrm{HC}$ were taken from standard hospital records. Body surface area (BSA) was calculated using the following equation [17]:

$$
\mathrm{BSA}=\sqrt{\left[\frac{\mathrm{BL}(\mathrm{cm}) \times \mathrm{BW}(\mathrm{kg})}{3600}\right]} .
$$

2.2. Blood Pressure Measurements. A diascope oscillometer (Artema) was used to determine systolic and diastolic blood pressure (SBP or DBP, resp.), and only one of the investigators performed all of the blood pressure (BP) measurements using a standardized protocol. The smallest cuff size that covered at least two thirds of the right upper arm and encompassed the entire arm was selected. BP was measured in a supine position on the 3rd day after delivery. Newborn measurements were taken at least one and a half hours following their last feeding or medical intervention. An appropriately sized cuff was applied to the right upper arm, and the newborn was then left undisturbed for at least 15 minutes or until the infant was sleeping or in a quiet awake state. Three successive BP recordings were taken at three-minute intervals.

2.3. Echocardiographic Measurements. Echocardiographic measurements in newborn on the 3rd day after delivery were made by one pediatric cardiologist. Two-dimensional M-mode echocardiography was performed using an Acuson Sequoia 512 unit (USA), equipped with a $2-4 \mathrm{MHz}$ imaging transducer. Measurement techniques were consistent with the American Society of Echocardiography conventions. In a parasternal long-axis view, LVIDd-left ventricular internal diameter-diastolic, LVIDs-left ventricular internal diametersystolic, LVPW-left ventricular posterior wall thickness at end diastole, IVS-thickness of interventricular septum at end diastole, LAD-left atrial diameter, AoD-aortic diameter, PAD-pulmonary artery diameter, LVV-left ventricular volume, and LVEF-left ventricular ejection fraction were measured (using M-mode formulas). The left ventricular masses (LVM) were calculated from the echocardiographic left ventricular dimension measurements, using the Penn convention with the equation modified by Huwez et al. [18] (1994) as follows:

$$
\mathrm{LVM}=1.04\left[(\mathrm{IVST}+\mathrm{LVPWT}+\mathrm{LVID})^{3}-\mathrm{LVID}^{3}\right],
$$

where IVST, LVPWT, and LVID denote interventricular septal thickness, left ventricular posterior wall thickness, and left ventricular internal dimension, respectively. To accurately determine and standardize the left ventricular mass, the LVM was indexed with respect to body length (LVM/BL $(\mathrm{g} / \mathrm{m}))$, body weight (LVM/BW $(\mathrm{g} / \mathrm{kg}))$, and body surface area $\left(\mathrm{LVM} / \mathrm{BSA}\left(\mathrm{g} / \mathrm{m}^{2}\right)\right)$, respectively.

2.3.1. Genetic Analysis. Genomic DNA from cord blood was isolated using the QIAamp Blood DNA Mini Kit (QIAGEN, Germany), according to the manufacturer's protocol. For the analysis of the intergenic G>A CALM2 
TABLE 1: Clinical and echocardiographic characteristics of the newborns in regard to gender.

\begin{tabular}{lccc}
\hline & Total & Males & Females \\
\hline$n(\%) n=206$ & 206 & $114(55.3 \%)$ & $92(44.7 \%)$ \\
BL $(\mathrm{m})$ & $0.6 \pm 0.0$ & $0.56 \pm 0.0$ & $0.55 \pm 0.0$ \\
BW $(\mathrm{kg})$ & $3.6 \pm 0.5$ & $3.6 \pm 0.5$ & $3.4 \pm 0.7$ \\
BSA $\left(\mathrm{m}^{2}\right)$ & $0.2 \pm 0.0$ & $0.2 \pm 0.0$ & $0.2 \pm 0.0$ \\
SBP $(\mathrm{mmHg})$ & $69.6 \pm 9.0$ & $69.2 \pm 9.9$ & $68.9 \pm 7.7$ \\
DBP $(\mathrm{mmHg})$ & $40.0 \pm 7.8$ & $40.0 \pm 8.1$ & $40.2 \pm 7.6$ \\
MAP $(\mathrm{mmHg})$ & $51.4 \pm 7.6$ & $51.8 \pm 8.0$ & $52.0 \pm 7.2$ \\
LVDd $(\mathrm{mm})$ & $18.6 \pm 1.6$ & $18.7 \pm 1.7$ & $18.5 \pm 1.6$ \\
LVDs $(\mathrm{mm})$ & $11.6 \pm 1.4$ & $12.0 \pm 1.3$ & $11.7 \pm 1.4$ \\
IVS $(\mathrm{mm})$ & $3.76 \pm 0.7$ & $3.7 \pm 0.7$ & $3.8 \pm 0.6$ \\
LVPW $(\mathrm{mm})$ & $2.8 \pm 0.7$ & $2.7 \pm 0.7$ & $2.8 \pm 0.7$ \\
LVM $(\mathrm{g})^{\ddagger}$ & $9.9 \pm 2.8$ & $43.1 \pm 11.4$ & $42.2 \pm 11.6$ \\
LVV $(\mathrm{mL})^{\ddagger}$ & $10.7 \pm 2.5$ & $10.8 \pm 2.5$ & $10.5 \pm 2.4$ \\
LVM/BL $(\mathrm{g} / \mathrm{m})^{\ddagger}$ & $17.7 \pm 4.8$ & $18.0 \pm 4.8$ & 0.028 \\
LVM/BW $(\mathrm{g} / \mathrm{kg})^{\ddagger}$ & $2.96 \pm 0.8$ & $2.9 \pm 0.8$ & 0.309 \\
LVM/BSA $\left(\mathrm{g} / \mathrm{m}^{2}\right)^{\ddagger}$ & $42.76 \pm 11.5$ & $43.1 \pm 11.4$ & 0.565 \\
\hline
\end{tabular}

${ }^{\ddagger}$ Adjusted for SBP and DPB.

MAP: mean arterial pressure.

(rs7565161) polymorphism, a polymerase chain reactionrestriction fragment length polymorphism (PCR/RFLP) method was designed with the following primer pair: forward $5^{\prime}$-AgggCCTgCAATCTAAT- $3^{\prime}$ and reverse $5^{\prime}$ ATATAATCCCCACCTTCAg-3' (TIB MOL BIOL, Poznań, Poland). The CALM amplicons were subsequently digested with the AciI restriction enzyme (MBI Fermentas, Vilnius, Lithuania). The PCR product of 417 base pairs (bp) was cut into fragments of $258 \mathrm{bp}, 137 \mathrm{bp}$, and $22 \mathrm{bp}$ in the presence of the $G$ allele and into fragments of $395 \mathrm{bp}$ and $22 \mathrm{bp}$ in the presence of the A allele. Restriction fragments in each case were electrophoretically separated and visualized in midori green-stained (Nippon Genetics) 3\% agarose gels. To verify the results, sequencing analyses were performed. All tested individuals had genotypes confirmed by sequencing. Each CALM2 amplicon was cleaned with GenElute PCR Clean-Up Kit (Sigma). Sequencing was performed according to the dideoxy Sanger method in a GeneAmp PCR System 9700 thermal cycler (Applied Biosystems), using BigDye Terminator v3.1 Cycle Sequencing Kit (Applied Biosystems). Afterwards, samples were purified (BigDye XTerminator Purification Kit, Applied Biosystems), and $20 \mu \mathrm{L}$ deionized formamide (Applied Biosystems) was added. Sequencing analysis using an ABI PRISM 3100-Avant machine (Applied Biosystems) was performed. The sequencing results were read using Sequencing Analysis Software v5.1 (Applied Biosystems). In each case, the result obtained with PCRRFLP method was identical with that appropriate one from sequencing.

2.4. Statistical Analysis. The divergence of CALM2 genotypes frequencies from Hardy-Weinberg equilibrium was assessed using $\chi^{2}$ tests, and the distribution of each quantitative variable was tested for skewness. Quantitative data were presented as means \pm SD and analyzed either by Student's $t$-test or by one-way ANOVA. Left ventricular mass indexes (LVMIs) were tested for association with genotype using multivariate analysis (ANCOVA) in order to adjust for possible confounding factors: neonatal (gestational age, gender, SBP, and APGAR at three minutes) and maternal (age, BMI at the beginning and the end of the pregnancy, smoking status, and hypertension status). Dominant, recessive, and additive modes of inheritance were tested. Statistical significance was defined as $P<0.05$. All data were analyzed with STATISTICA (data analysis software system, version 10.0, StatSoft, Inc. 2011, http://www.statsoft.com/).

\section{Results}

Characteristics of the newborn cohort $(n=206)$ are shown in Table 1. The distribution of these characteristics in our cohort approached normality (skewness $<2$ for all variables). Mean BW and BSA values in boy newborns were significantly higher than those in girls. SBP measurements were also higher than those in girls. 69 GG CALM2 homozygotes (33.5\%), 95 GA heterozygotes (46.1\%), and 42 AA homozygotes $(20.4 \%)$ were identified. There were no significant differences in CALM2 genotype or allele distributions between boys and girls $(P=0.273$, and $P=0.107$, resp.). The CALM genotype distributions conformed to the expected HardyWeinberg equilibrium $(P=0.396)$.

LVMI measurements were tested for association using multivariate analysis (ANCOVA) in order to adjust for possible confounding factors, after adjusting for newborn (gestational age, gender, SBP, and APGAR at three minutes) and maternal (age, BMI at the beginning and the end of the pregnancy, smoking status, and hypertension status) parameters. We revealed a significant association between 
TABLE 2: Overview of results depending on fetal genotypes.

\begin{tabular}{|c|c|c|c|c|}
\hline & $\begin{array}{c}\mathrm{GG} \\
n=69\end{array}$ & $\begin{array}{c}\mathrm{GA} \\
n=95\end{array}$ & $\begin{array}{c}\text { AA } \\
n=42\end{array}$ & $P$ \\
\hline Gender M/F & $42 / 47(37 \% / 29 \%)$ & $53 / 42(46 \% / 46 \%)$ & $19 / 23(17 \% / 25 \%)$ & 0.273 \\
\hline Gestational age (weeks) & $39.3 \pm 0.9$ & $39.5 \pm 1.0$ & $39.0 \pm 1.0$ & 0.019 \\
\hline Birth weight (kg) & $3.48 \pm 0.46$ & $3.5 \pm 0.43$ & $3.4 \pm 0.47$ & 0.503 \\
\hline Neonatal body length (cm) & $0.56 \pm 0.03$ & $0.56 \pm 0.03$ & $0.55 \pm 0.03$ & 0.384 \\
\hline Neonatal head circumference $(\mathrm{cm})$ & $33.9 \pm 1.5$ & $33.7 \pm 1.3$ & $34.1 \pm 1.3$ & 0.633 \\
\hline Apgar 3 min & $9.7 \pm 0.9$ & $9.6 \pm 0.8$ & $9.5 \pm 1.3$ & 0.734 \\
\hline $\mathrm{SBP}(\mathrm{mmHg})$ & $68.7 \pm 8.0$ & $68.8 \pm 9.1$ & $70.4 \pm 10.4$ & 0.574 \\
\hline SBP $\geq 90$ percentile $n,(\%)$ & $4(40,0)$ & $9(45,0)$ & $7(35,0)$ & 0.173 \\
\hline $\mathrm{DBP}(\mathrm{mmHg})$ & $39.5 \pm 7.4$ & $40.0 \pm 7.4$ & $41.0 \pm 9.5$ & 0.634 \\
\hline $\mathrm{DBP} \geq 90$ percentile & $5(23.8)$ & $7(33.3)$ & $9(42.9)$ & 0.027 \\
\hline MAP (mmHg) & $51.5 \pm 7.1$ & $52.0 \pm 6.9$ & $52.4 \pm 9.9$ & 0.830 \\
\hline MAP $\geq 90$ percentile & $6(27.27)$ & $9(40.91)$ & $7(31.82)$ & 0.373 \\
\hline Maternal age (years) & $28.2 \pm 6.0$ & $27.7 \pm 5.2$ & $29.3 \pm 4.5$ & 0.274 \\
\hline $\begin{array}{l}\text { Smoking habits } \\
\text { History during pregnancy } n,(\%)\end{array}$ & $7(33.33)$ & $11(52.38)$ & $3(14.29)$ & 0.731 \\
\hline $\begin{array}{l}\text { Hypertension } \\
\text { History during pregnancy or } \\
\text { history of hypertension } n,(\%)\end{array}$ & $3(17.65)$ & $8(47.06)$ & $6(35.29)$ & 0.182 \\
\hline $\begin{array}{l}\mathrm{BMI}\left(\mathrm{kg} / \mathrm{m}^{2}\right) \text { at the beginning of } \\
\text { pregnancy }\end{array}$ & $21.7 \pm 2.9$ & $22.2 \pm 3.6$ & $22.9 \pm 4.7$ & 0.251 \\
\hline BMI $\left(\mathrm{kg} / \mathrm{m}^{2}\right)$ at the end of pregnancy & $27.3 \pm 3.6$ & $28.0 \pm 4.0$ & $27.7 \pm 4.6$ & 0.539 \\
\hline Parity & $1.6 \pm 08$ & $1.4 \pm 0.8$ & $1.6 \pm 0.9$ & 0.292 \\
\hline
\end{tabular}

LVMIs (LVM/BW in recessive and additive modes and the CALM2 polymorphism). The carriers of the $\mathrm{G}$ allele of the CALM2 polymorphism had significantly higher LVM/BW values, when compared with newborns homozygous for the A allele $\left(3.1 \mathrm{~g} / \mathrm{m}^{2}\right.$ versus $2.5 \mathrm{~g} / \mathrm{m}^{2}, P_{\text {adjusted }}=0.036$, resp.). The AG genotype of CALM2 was associated with the highest values of LVM/BW, exhibiting a pattern of heterozygote advantage $\left(2.9 \mathrm{~g} / \mathrm{kg}\right.$ versus $3.1 \mathrm{~g} / \mathrm{kg}$ versus $2.5 \mathrm{~g} / \mathrm{kg}, P_{\text {adjusted }}=$ 0.037 ) (Figures 2 and 3 ). Carriers of the A allele did not differ in LVM indexes (Figure 1).

An association was observed between genotype and DBP $\geq 90$ percentile $(P=0.027)$. Carriers of the allele $\mathrm{A}$ of the CALM2 gene had an increased incidence (\%) SBP $\geq$ 90 percentile $(P=0.027,76.2 \%$ versus $23.8 \%)$. Lastly, the CALM2 polymorphism was significantly correlated with maternal history of gestational age $(P=0.019)$. An overview over the data can be found in Table 2 .

\section{Discussion}

Genetic factors are estimated to be responsible for between $30 \%$ and $70 \%$ of cardiac mass variance [19]. Studies in twins $[20,21]$ and populations $[22,23]$ showed that LVM is under genetic control.

The present study in a cohort of newborns has demonstrated for the first time the significant association between variants of the intergenic adjacent CALM2 polymorphism and increases in LVM indices in newborns. Proper assessment of heart size in the newborn still stirs controversy.

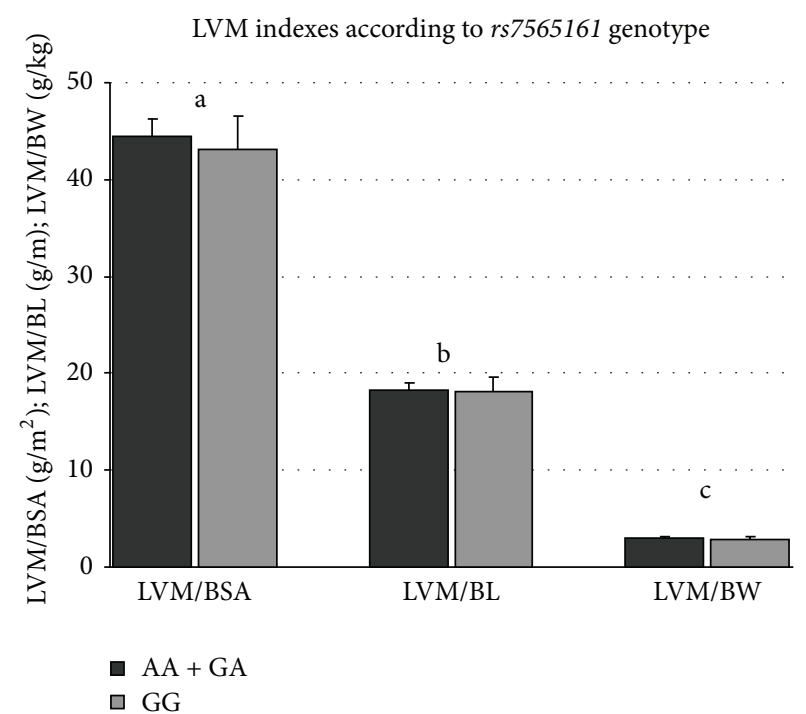

FIGURE 1: LVM indexes according to $r s 7565161$ genotype. Mean and SEM are shown. ${ }^{\mathrm{a}} \mathrm{P}=0.574 ;{ }^{\mathrm{b}} \mathrm{P}=0.795 ;{ }^{\mathrm{c}} \mathrm{P}=0.404 ;{ }^{\mathrm{a}, \mathrm{b}, \mathrm{c}} \mathrm{AA}+\mathrm{GA}$ versus GG.

Therefore, to minimize the disparities, we carefully selected homogenous group of full-term newborns. To accurately determine LVM, we used LVM in relation to BSA, BL, and $\mathrm{BW}$, which are reported to be more appropriate. It should be emphasized that confounding factors such as especially gestational age may play a role in the development of LVM 


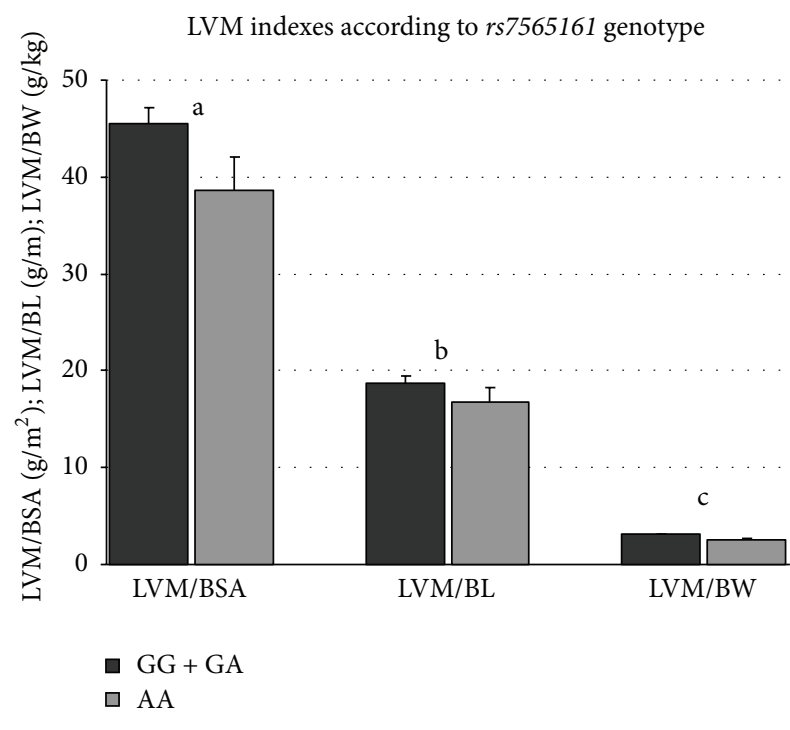

FIGURE 2: LVM indexes according to $r s 7565161$ genotype. Mean and SEM are shown. ${ }^{\mathrm{a}} \mathrm{P}=0.075 ;{ }^{\mathrm{b}} \mathrm{P}=0.172 ;{ }^{\mathrm{c}} \mathrm{P}=0.036 ;{ }^{\mathrm{a}, \mathrm{b}, \mathrm{c}} \mathrm{GG}+\mathrm{GA}$ versus AA.

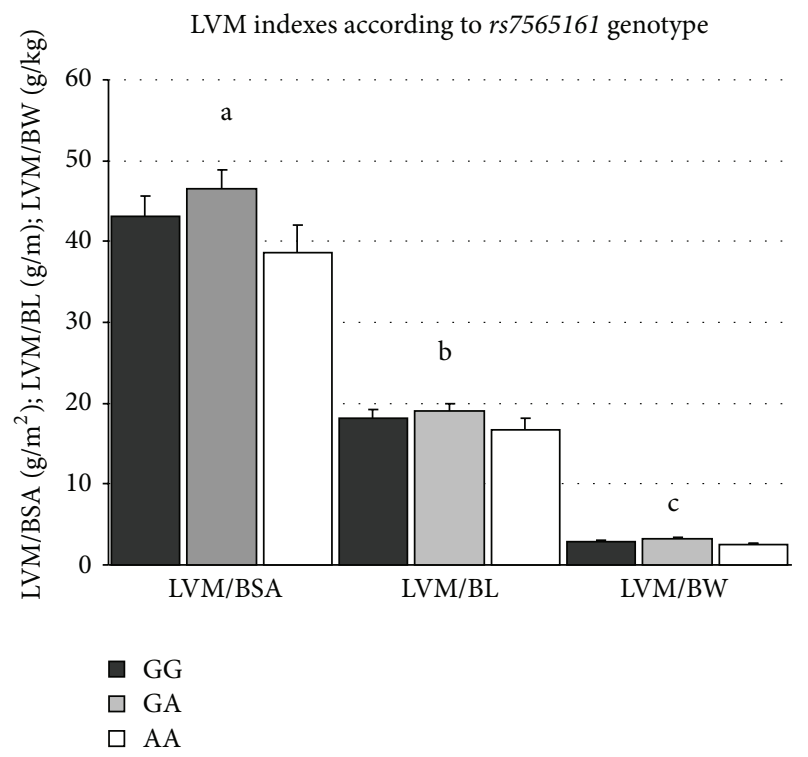

FIGURE 3: LVM indexes according to $r s 7565161$ genotype. Mean and SEM are shown. ${ }^{\mathrm{a}} \mathrm{P}=0.109 ;{ }^{\mathrm{b}} \mathrm{P}=0.306 ;{ }^{\mathrm{c}} \mathrm{P}=0.037 ;{ }^{\mathrm{a}, \mathrm{b}, \mathrm{c}} \mathrm{GG}$ versus GA versus AA.

in fetus. The fetal programming hypothesis states that, for example, birth mass in newborns may be partially related to maternal factors [24]. In this study, the AG genotype of intergenic adjacent CALM2 polymorphism was associated with the subtle higher values of LVMI, exhibiting a pattern of heterozygote advantage in results. What is important, in our study, the carriers of the G allele have higher LVM than the carriers of the A allele. These results were similar to those of a large cohort of adults, who were studied by Vasan et al. [16]. In this meta-analysis of echocardiographic data associated with interindividual variation in cardiac dimension, the polymorphism of CALM2 gene rs7565161 was associated with
LVM. It should be mentioned that total sample included those with coronary heart disease, peripheral vascular disease, valvular heart disease, stroke, and circulation heart failure. These risk factors may also increase the effect of the gene.

Current results exhibit a pattern of heterozygote advantage, as heterozygote newborns had significantly higher LVMI than the carriers of homozygote genotypes. The heterozygote advantage hypothesis attributes heterosis to the superior fitness of heterozygous genotypes over homozygous genotypes at a single locus [25]. Some studies suggest that heterozygote advantage is a favorable process, the positive selection over evolution, as a natural consequence of adaptation role of variation in gene [26-28]. However, in light of Vasan's study [16], the feature that may be potentially beneficial in early life may lead to predisposition to increase or hypertrophy left ventricular in adults. Williams suggested "antagonistic pleiotropy" theory, which assumes that some genes responsible for increased fitness in the children, fertile organism contribute to decreased fitness in adults [29]. We conclude that this theory may be relevant here. We hypothesized that genetic variation in the intergenic adjacent CALM2 gene polymorphism, analogously to the other common polymorphisms in developmental genes, may cause minor changes in the development or modulation of LVM in newborns.

We continue observing our population and consider conducting follow-up, which will show in later years whether the heterozygotes have a predisposition to develop left ventricular hypertrophy or not. However, our results require confirmation in further independent large studies.

The connection between calmodulin and modulating cardiac contractile function and growth is well documented $[30,31]$. Otherwise, in an experimental animal study, the protein level of CaM was shown with a relatively high level of calmodulin appearing on gestational days 14-15, followed by a steady but significant decrease at birth and during the first week of postnatal life [32]. It is reported that specific elevation of CaM levels directly affects the rate of cell proliferation [33]. Also, Gillett et al. [34], in animal study (fetal sheep), showed that increased CALM2 mRNA expression levels may reflect an important role for calmodulin in expansion-induced fetal lung growth. A study performed in human showed that genes encoding calmodulin (CALM1, CALM2, and CALM3) are involved in increasing proliferation $[35,36]$.

Although such knowledge indicates the important role of calmodulin-dependent protein kinases and phosphatases in regulating cardiac hypertrophy [4], the role of genetic variation in $\mathrm{CaM}$ in the physiology of the development human heart has not been clarified. Our results suggest that genetic variation of CALM2 may be partly involved in regulating myocardial cell proliferation and growth, during embryogenesis and in the first days of life. It is possible that genetic variation in CaM may have been involved in regulating the activity or/and levels in serum kinases and phosphorylases (e.g., CaMKII, calcineurin) during fetal life. In the current study, we investigated healthy newborns born at full term. Our previous studies reported that RAS (reninangiotensin system) or BMP4 (bone morphogenetic protein 4) and BMPR1A (bone morphogenetic protein, receptor 
type 1A) genetic variation may partially account for subtle variation in LVM or parameters or heart parameters in newborns $[37,38]$. To the best of our knowledge, the recent results have never been replicated, and therefore the replication of the study findings in different population is needed.

Additionally, an association between CALM2 polymorphism, and DBP and MAP was found, but the mechanism by which this might act is not clear. Blood pressure is regulated by multiple neuronal, hormonal, renal, and vascular control mechanisms, as well as genetic and environmental factors. It is also dependent, inter alia, on the force of contraction of the heart muscle which is connected indirectly to the left ventricular mass. There are many known candidate genes that have huge influence on the blood pressure or development of hypertension [39-41]. However, the mechanisms of interaction intensifying effects of these genes are still researched. It is known that changes in signaling mechanisms in the endothelium of vascular smooth muscle (VSM) cause alterations in vascular tone and blood vessel remodeling and may lead to persistent increase in vascular resistance. Vascular tone that is a component of regulating blood pressure can be controlled indirectly by different genes activity. It is known that CaM regulates various proteins. An experimental study demonstrated findings that expression levels of several CaMrelated proteins are changed in vascular tissues and suggested that CaM-related proteins might be at least in part related to the pathogenesis of hypertensive vascular diseases [42]. A recent study reported that CaMKII inhibitor inhibited the Ang II-induced vascular smooth muscle cell hypertrophy [43]. However, the role of CaM-related protein in vascular pathophysiology is not yet fully clarified. Further studies are necessary to clarify it.

In conclusion, we have shown that the intergenic adjacent CALM2 polymorphism is associated with left ventricular mass in newborns. This might be the consequences of variation in cell proliferation and growth, and this finding may indicate an important role for genetic variation of CALM2 in expansion-induced heart growth in fetal life.

\section{Conflict of Interests}

The authors declare no conflict of interests.

\section{Acknowledgment}

The authors are grateful to Dr. Jeremy Clark, a native speaker experienced in scientific English, for checking the paper.

\section{References}

[1] D. Levy, R. J. Garrison, D. D. Savage, W. B. Kannel, and W. P. Castelli, "Prognostic implications of echocardiographically determined left ventricular mass in the Framingham Heart Study," The New England Journal of Medicine, vol. 322, no. 22, pp. 1561-1566, 1990.

[2] N. Frey and E. N. Olson, "Cardiac hypertrophy: the good, the bad, and the ugly," Annual Review of Physiology, vol. 65, pp. 4579, 2003.
[3] G. E. Hardingham and H. Bading, "Nuclear calcium: a key regulator of gene expression," BioMetals, vol. 11, no. 4, pp. 345358, 1998.

[4] R. Passier, H. Zeng, N. Frey et al., "CaM kinase signaling induces cardiac hypertrophy and activates the MEF2 transcription factor in vivo," Journal of Clinical Investigation, vol. 105, no. 10, pp. 1395-1406, 2000.

[5] H. L. Sweeney, B. F. Bowman, and J. T. Stull, "Myosin light chain phosphorylation in vertebrate striated muscle: regulation and function," American Journal of Physiology, vol. 264, no. 5, pp. C1085-C1095, 1993.

[6] P. Ding, J. Huang, P. K. Battiprolu, J. A. Hill, K. E. Kamm, and J. T. Stull, "Cardiac myosin light chain kinase is necessary for myosin regulatory light chain phosphorylation and cardiac performance in vivo," Journal of Biological Chemistry, vol. 285, no. 52, pp. 40819-40829, 2010.

[7] A. P. Braun and H. Schulman, "The multifunctional calcium/ calmodulin-dependent protein kinase: from form to function," Annual Review of Physiology, vol. 57, pp. 417-445, 1995.

[8] B. Li, J. R. Dedman, and M. A. Kaetzel, "Nuclear $\mathrm{Ca}^{2+} /$ calmodulin-dependent protein kinase II in the murine heart," Biochimica et Biophysica Acta, vol. 1763, no. 11, pp. 1275-1281, 2006.

[9] T. Zhang, L. S. Maier, N. D. Dalton et al., "The $\delta_{\mathrm{C}}$ isoform of CaMKII is activated in cardiac hypertrophy and induces dilated cardiomyopathy and heart failure," Circulation Research, vol. 92, no. 8, pp. 912-919, 2003.

[10] D. Hagemann, J. Bohlender, B. Hoch, E.-G. Kraus, and P. Karczewski, "Expression of $\mathrm{Ca}^{2+} /$ calmodulin-dependent protein kinase II $\delta$-subunit isoforms in rats with hypertensive cardiac hypertrophy," Molecular and Cellular Biochemistry, vol. 220, no. 1-2, pp. 69-76, 2001.

[11] T. Zhang and J. H. Brown, "Role of $\mathrm{Ca}^{2+} /$ calmodulin-dependent protein kinase II in cardiac hypertrophy and heart failure," Cardiovascular Research, vol. 63, no. 3, pp. 476-486, 2004.

[12] T. Zhang, E. N. Johnson, Y. Gu et al., "The cardiac-specific nuclear $\delta \mathrm{B}$ isoform of $\mathrm{Ca}^{2+} /$ calmodulin-dependent protein kinase II induces hypertrophy and dilated cardiomyopathy associated with increased protein phosphatase 2A activity," Journal of Biological Chemistry, vol. 277, no. 2, pp. 1261-1267, 2002.

[13] K. E. Fladmark, O. T. Brustugun, G. Mellgren et al., " $\mathrm{Ca}^{2+}$ / calmodulin-dependent protein kinase II is required for microcystin-induced apoptosis," Journal of Biological Chemistry, vol. 277, no. 4, pp. 2804-2811, 2002.

[14] H. Mototani, A. Iida, Y. Nakamura, and S. Ikegawa, "Identification of sequence polymorphisms in CALM2 and analysis of association with hip osteoarthritis in a Japanese population," Journal of Bone and Mineral Metabolism, vol. 28, no. 5, pp. 547553, 2010.

[15] T. Liu, L. Xie, J. Ye, Y. Liu, and X. He, "Screening of candidate genes for primary open angle glaucoma," Molecular Vision, vol. 18, pp. 2119-2126, 2012.

[16] R. S. Vasan, N. L. Glazer, J. F. Felix et al., "Genetic variants associated with cardiac structur and function," JAMA, vol. 302, no. 2, pp. 168-178, 2009.

[17] R. D. Mosteller, "Simplified calculation of body-surface area," The New England Journal of Medicine, vol. 317, no. 17, p. 1098, 1987.

[18] F. U. Huwez, A. B. Houston, J. Watson, S. McLaughin, and P. W. Macfarlane, "Age and body surface area related normal upper 
and lower limits of M mode echocardiographic measurements and left ventricular volume and mass from infancy to early adulthood," British Heart Journal, vol. 72, no. 3, pp. 276-280, 1994.

[19] H. A. Verhaaren, R. M. Schieken, M. Mosteller, J. K. Hewitt, L. J. Eaves, and W. E. Nance, "Bivariate genetic analysis of left ventricular mass and weight in pubertal twins (The Medical College of Virginia Twin Study)," American Journal of Cardiology, vol. 68, no. 6, pp. 661-668, 1991.

[20] L. Swan, D. H. Birnie, S. Padmanabhan, G. Inglis, J. M. C. Connell, and W. S. Hillis, "The genetic determination of left ventricular mass in healthy adults," European Heart Journal, vol. 24, no. 6, pp. 577-582, 2003.

[21] P. Sharma, R. P. S. Middelberg, T. Andrew, M. R. Johnson, H. Christley, and M. J. Brown, "Heritability of left ventricular mass in a large cohort of twins," Journal of Hypertension, vol. 24, no. 2, pp. 321-324, 2006.

[22] J. N. Bella, J. W. MacCluer, M. J. Roman et al., "Heritability of left ventricular dimensions and mass in American Indians: the Strong Heart Study," Journal of Hypertension, vol. 22, no. 2, pp. 281-286, 2004.

[23] T. L. Assimes, B. Narasimhan, T. B. Seto et al., "Heritability of left ventricular mass in Japanese families living in Hawaii: the SAPPHIRe study," Journal of Hypertension, vol. 25, no. 5, pp. 985-992, 2007.

[24] L. Li, K. Lu, Z. Chen, T. Mu, Z. Hu, and X. Li, "Dominance, overdominance and epistasis condition the heterosis in two heterotic rice hybrids," Genetics, vol. 180, no. 3, pp. 1725-1742, 2008.

[25] K. J. Meyers, T. H. Mosley, E. Fox et al., "Genetic variations associated with echocardiographic left ventricular traits in hypertensive blacks," Hypertension, vol. 49, no. 5, pp. 992-999, 2007.

[26] A. Santovito, P. Cervella, D. Schleicherova, and M. Delpero, "Genotyping for cytokine polymorphisms in a Northern Ivory Coast population reveals a high frequency of the heterozygote genotypes for the TNF- $\alpha$-308G/A SNP," International Journal of Immunogenetics, 2012.

[27] G. Y. Miasnikova, A. I. Sergueeva, M. Nouraie et al., "The heterozygote advantage of the chuvash polycythemia $\mathrm{VHL}^{\mathrm{R} 200 \mathrm{~W}}$ mutation may be protection against anemia," Haematologica, vol. 96, no. 9, pp. 1371-1374, 2011.

[28] D. Sellis, B. J. Callahan, D. A. Petrov, and P. W. Messer, "Heterozygote advantage as a natural consequence of adaptation in diploids," Proceedings of the National Academy of Sciences of the United States of America, vol. 108, no. 51, pp. 20666-20671, 2011.

[29] G. C. Williams, "Plejotropy, natural selection and the evolution of senescence," Evolution, vol. 11, pp. 398-411, 1957.

[30] S. Chang, T. A. McKinsey, C. L. Zhang, J. A. Richardson, J. A. Hill, and E. N. Olson, "Histone deacetylases 5 and 9 govern responsiveness of the heart to a subset of stress signals and play redundant roles in heart development," Molecular and Cellular Biology, vol. 24, no. 19, pp. 8467-8476, 2004.

[31] J. D. Molkentin, J.-R. Lu, C. L. Antos et al., "A calcineurindependent transcriptional pathway for cardiac hypertrophy," Cell, vol. 93, no. 2, pp. 215-228, 1998.

[32] A. K. S. Ho, K. Shang, and R. Duffield, "Calmodulin regulation of the cholinergic receptor in the rat heart during ontogeny and senescence," Mechanisms of Ageing and Development, vol. 36, no. 2, pp. 143-154, 1986.
[33] C. D. Rasmussen and A. R. Means, "Calmodulin is involved in regulation of cell proliferation," The EMBO Journal, vol. 6, no. 13, pp. 3961-3968, 1987.

[34] A. M. Gillett, M. J. Wallace, M. T. Gillespie, and S. B. Hooper, "Increased expansion of the lung stimulates calmodulin 2 expression in fetal sheep," American Journal of Physiology, vol. 282, no. 3, pp. L440-L447, 2002.

[35] S. L. Toutenhoofd, D. Foletti, R. Wicki et al., "Characterization of the human CALM2 calmodulin gene and comparison of the transcriptional activity of CALM1, CALM2 and CALM3," Cell Calcium, vol. 23, no. 5, pp. 323-338, 1998.

[36] J. Colomer, N. Agell, P. Engel, and O. Bachs, "Expression of calmodulin and calmodulin binding proteins in lymphoblastoid cells," Journal of Cellular Physiology, vol. 159, no. 3, pp. 542-550, 1994.

[37] I. Gorący, G. Dawid, B. Łoniewska, J. Gorący, and A. Ciechanowicz, "Genetics of the rennin-angitensin system with respect to cardiac and blood pressure phenotypes in healthy newborns infants," Journal of Renin-Angiotensin-Aldosterone System.

[38] I. Gorący, K. Safranow, and G. Dawid, "Common genetic variants of BMP4, BMPR1A, BMPR1B and ACVR1 genes, left ventricular mass and other parameters of heart in newborns," Genetic Testing Molecular Biomarkerks, vol. 16, no. 11, pp. 13091316, 2012.

[39] Y. S. Cho, M. J. Go, Y. J. Kim et al., "A large-scale genome-wide association study of Asian populations uncovers genetic factors influencing eight quantitative traits," Nature Genetics, vol. 41, no. 5, pp. 527-534, 2009.

[40] C. Newton-Cheh, T. Johnson, V. Gateva et al., "Genome-wide association study identifies eight loci associated with blood pressure," Nature Genetics, vol. 41, no. 6, pp. 666-675, 2009.

[41] D. Levy, G. B. Ehret, K. Rice et al., "Genome-wide association study of blood pressure and hypertension," Nature Genetics, vol. 41, no. 6, pp. 677-687, 2009.

[42] T. Usui, M. Okada, Y. Hara, and H. Yamawaki, "Exploring calmodulin-related proteins, which mediate development of hypertension, in vascular tissues of spontaneous hypertensive rats," Biochemical and Biophysical Research Communications, vol. 405, no. 1, pp. 47-51, 2011.

[43] H. Li, W. Li, A. K. Gupta, P. J. Mohler, M. E. Anderson, and I. M. Grumbach, "Calmodulin kinase II is required for angiotensin II-mediated vascular smooth muscle hypertrophy," American Journal of Physiology, vol. 298, no. 2, pp. H688-H698, 2010. 

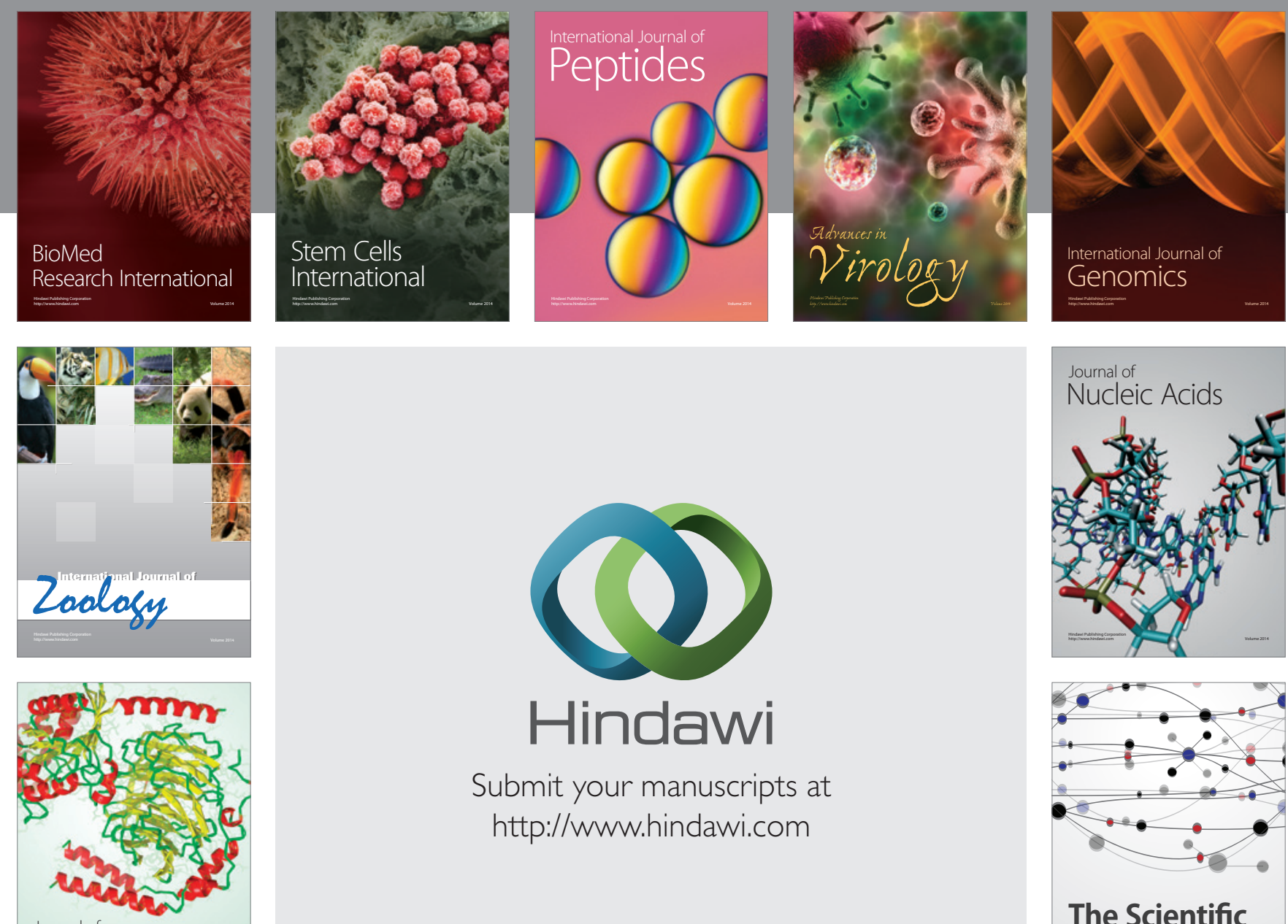

Submit your manuscripts at

http://www.hindawi.com

Journal of
Signal Transduction
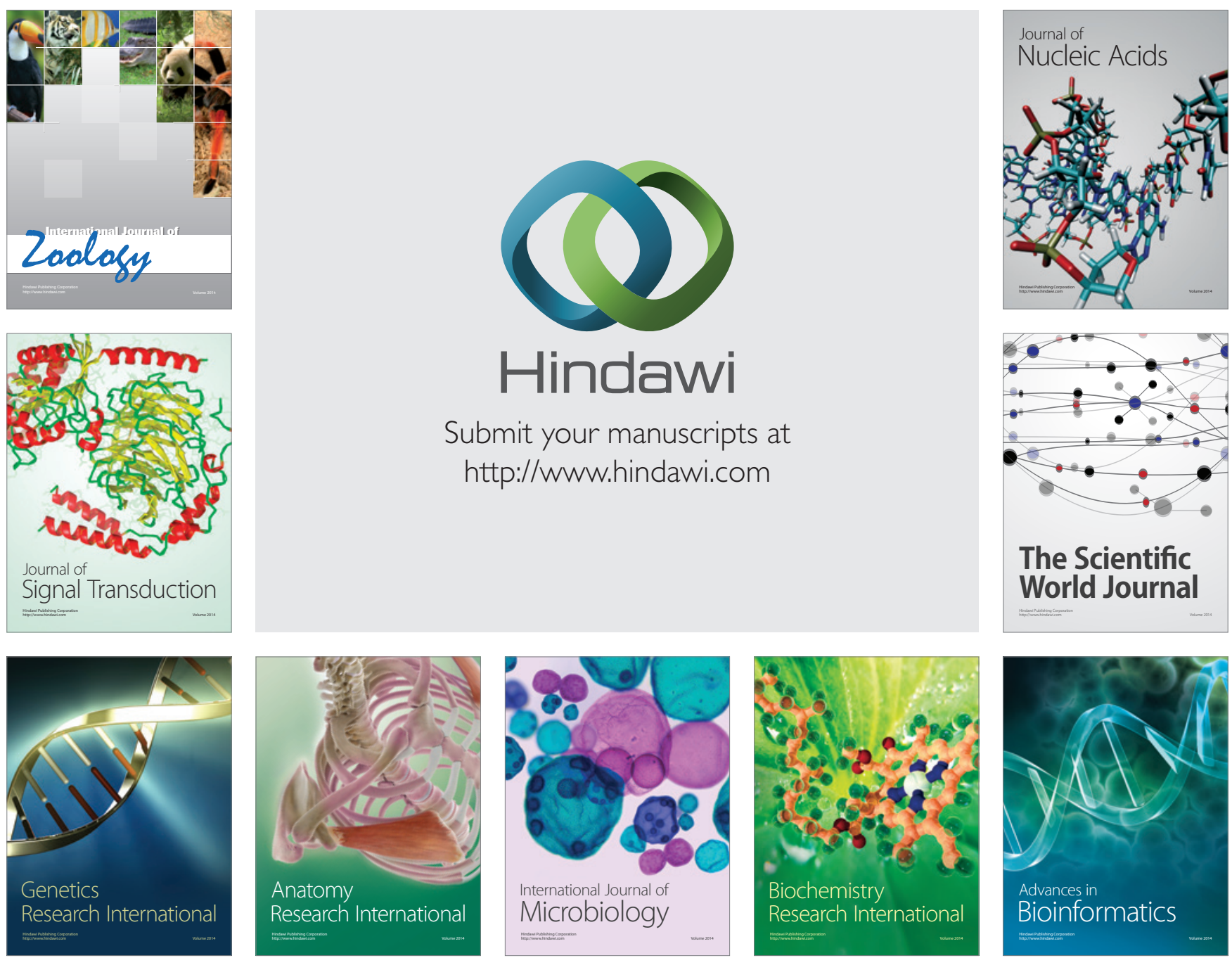

The Scientific World Journal
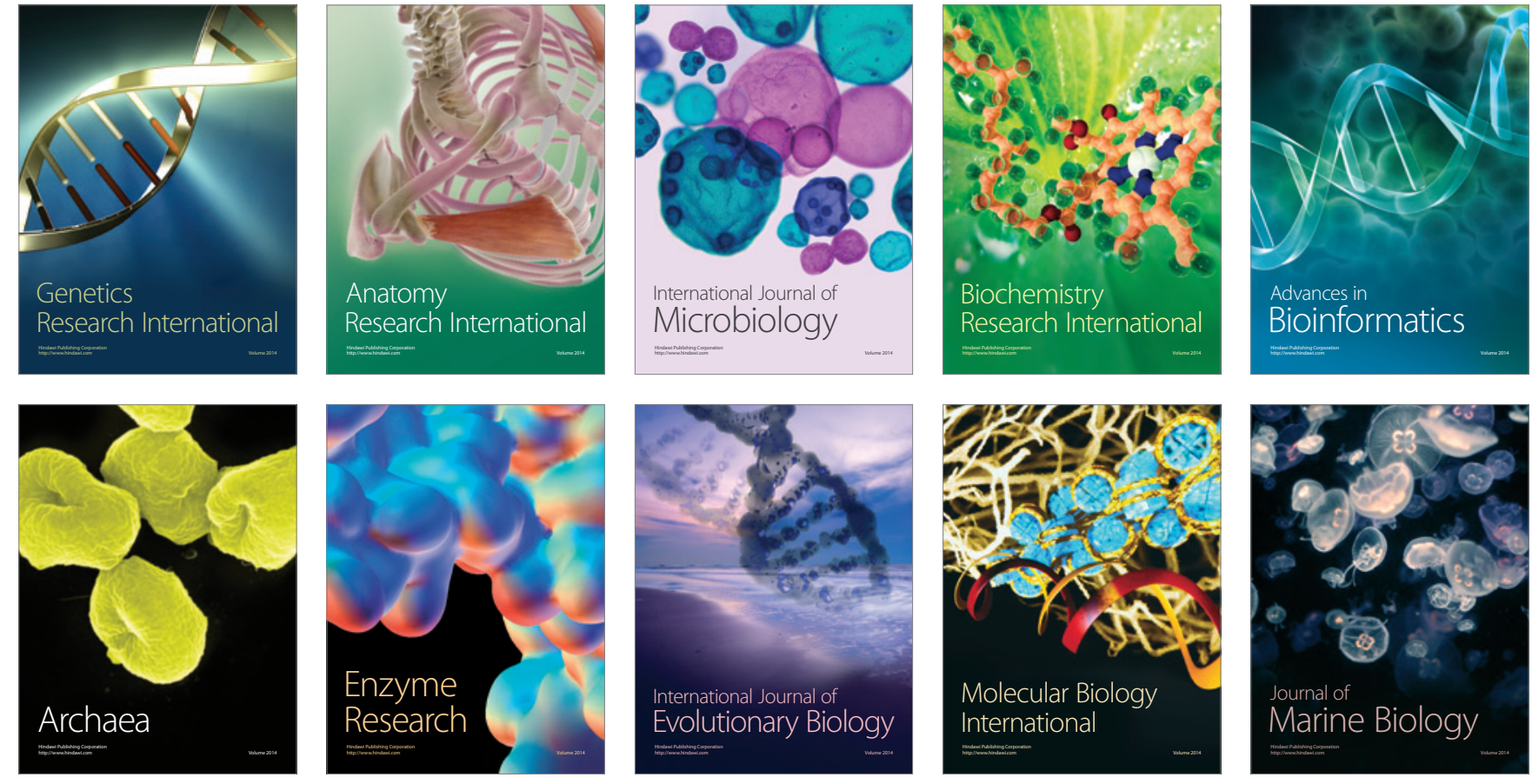